\title{
The Challenges Faced by Academia Preparing Students for Industry: What We Teach and What We Do
}

\author{
Lidia Oshlyansky \\ Reading Room \\ 65-66 Frith Street \\ London W1D 3JR \\ +44 (0) 2071732800 \\ Lidia@ readingroom.com
}

\author{
Paul Cairns \\ Dept of Computer Science \\ University of York \\ York, YO10 5DD UK \\ +44 (0)1904 434751
}

pcairns@cs.york.ac.uk

\author{
Angela Sasse \\ Dept of Computer Science \\ University College London \\ London WC1E 6BT UK \\ +44 (0) 2076797214 \\ a.sasse@cs.ucl.ac.uk
}

\author{
Chandra Harrison \\ Dept of Computer Science \\ University of York \\ York, YO10 5DD UK \\ +44 (0) 1940432722 \\ chandra.harrison@ \\ cs.york.ac.uk
}

\begin{abstract}
This workshop re-opens the discussion of the challenges faced by academia when preparing students to take jobs in industry. The workshop's goal is to develop a framework by which academia and industry can better communicate and resolve their differing needs and goals. The workshop will provide practical guidance for academia and industry to take forward and continue the dialogue.
\end{abstract}

\section{Categories and Subject Descriptors}

H.5.m Information Systems: Information Interfaces and Presentation: Miscellaneous

\section{General Terms}

Human Factors, Standardization, Theory.

\section{Keywords}

Industry, Academia, Teaching, Practice.

\section{INTRODUCTION}

The discussion around the gap between what we teach and what we do is not new and not unique to the field of HCI $[1,2,3,4]$. It is a discussion that may never be fully resolved and one that deserves occasional re-examination. In academia we teach students and hope that they will move successfully into careers in either research or industry. Positions in research and in academia are far fewer and more difficult to come by as so much depends on funding sources, successful grant applications and availability of academic posts. Industry however seems to have an unquenchable need for smart talented employees. In recent years this has been particularly true as the economy has stayed robust. As the importance of HCI has increased in the last decade, so has the need for students prepared to enter industry in various HCI roles.

There are many roles that students of $\mathrm{HCI}$ can apply to and successfully fill in industry. A sample of the roles posted on

(C) The Author 2008 .

Published by the British Computer Society various job and professional sites include:

- Information Architect

- User Interface Designer

- Interaction Designer

- Experience Architect / Designer / Analyst

- User Research

- Interface Specialist

- Web UI Engineer

- Usability Analyst / Specialist / Engineer

- User-Centred Design Analyst

- Human Factors Specialist / Analyst / Engineer

- User Experience Consultant / Researcher / Designer / Analyst

This is not an exhaustive list, but gives a good idea of the various labels that industry applies to the field of HCI. The roles listed above will also have a different scope of work and responsibilities; some will over lap others wont. For example, a "Web UI Engineer" may be asked to program in HTML and Flash, where as an "Information Architect" would be expected to be able to produce wire frames using Visio [6] or Axure [7]. Both roles may be asked to develop a user testing script for a usability evaluation session.

Students taking an undergraduate degree in Computer Science can often take electives in HCI and there are MSc programmes in $\mathrm{HCI}$ in many academic institutions. But a few undergraduate electives can not teach all the skills required for a professional career in HCI and an MSc cannot teach all of the skills needed for all of the various roles listed above. So the question for academia is: what skills to teach? Or is academia responsible for providing a solid underpinning so that graduating students can take up any position and learn on the job? Academia does, of course, teach skills needed in industry, but often this is as best practice rather than how they will be applied in reality. Are students able to apply the skills they learn once they graduate and does industry provide a setting in which these skills are applied as taught? For example, the agile development method so often used in industry would appear to be an ideal partner for the User Centred Design approach taught in HCI. The reality is that they are not easy to partner and do not automatically fit well together [5].

It is also not just the responsibility of academia to teach just for industry. Industry must also provide insight into the skills it requires and which of these are transferable from one role to another. Previous such discussions in related fields have found that academia and industry business have a different focus and different needs. Academia's focus is on the process of learning where as industry's is on the resulting end-product. Focusing too much on theory may produce a student that is unable to 
produce work and does not have applicable skills, where as focusing too much on skill would produce a student who did not have adaptable, transportable skills [1]. Ultimately, is academia responsible for teaching the general theoretical grounding and ensuring a well rounded understanding of the field or is it also responsible for providing real life craft skills? Is it then the responsibility of industry to provide concrete needs to academia and in turn fund education? Or is the reality a tentative balance between the extremes where a constant dialogue must take place between the two worlds?

\section{AIMS}

The aims of this workshop are three fold. First, it is to take stock of where we stand as both an academic and industry discipline on what we teach, what we research and what we do / apply in the real world. Second, it is to rejuvenate the dialogue between the two segments of our discipline about the needs and goals of each for learning and practice. Finally it is to develop a framework and suggestions in order to redress the gaps that exist on an ongoing basis. These aims can be summed up in the following two questions:

- Where is the field of HCI now in terms of incorporating the needs of industry to have well trained professionals and the needs of academia to move the field forward and have well rounded researchers?

- What is our ideal and do we reach it?

\section{ORGANISATION}

The workshop would like to invite position and opinion papers from academia and industry. These will be reviewed by the organisers and then openly discussed at the workshop. Participants will be asked to share specific goals and concerns about bridging the gap between the teaching and theory of HCI and the practice and application of it in the field. Participants will then be asked to form smaller discussion groups which will work to develop ideas and suggestions in the form of recommendation for the greater HCI community on how to address the gaps between teaching and practice. The final part of the workshop will be to consolidate the smaller discussion groups' suggestions into one larger coherent set of recommendations. Ideally the recommendations would be in the area of curriculum for students, industry involvement in the training and teaching of students and recommendations for building better communication between the two sectors. The results of the workshop will be presented as a poster in the conference.

\section{DESIRED OUTCOMES}

The workshop will hope to present to the conference a well discussed framework with which to move forward. This will include:

1. Recommendations for academia on possible changes to curriculum for both undergraduates and masters level students.

2. Recommendations for industry on how to become more involved in expressing their training needs and influencing student projects and teaching.

3. Practical recommendations for building more inclusive relationships and better communications between academia and business, not just for multi-national and large corporates but also for the small to medium businesses that employee $\mathrm{HCI}$ graduates.

The workshop participants will also be invited to participate in forming a permanent workgroup that will address these questions on a continuing basis in the British HCI community. The group will work to inform and influence the curriculum taught to students and the feedback and communications received from industry.

\section{REFERENCES}

[1] Swartz, C. S. Educating the Digital Artist for the Entertainment Industry: The Collision of Academia and Business. Panel, SIGGRAPH '97: Proceedings of the 24th annual conference on Computer graphics and interactive techniques. August, 1997, 456-458.

[2] Davis, S., Siau, K., \& Dhenuvakonda,K., A Fit-Gap Analysis of E-Business Curricula vs. Industry Needs. Communications of the ACM. 46, 12, (Dec 2003), 167177.

[3] Hitchcock, L., Industry Certification and Academic Degrees: Complementary, or Poles Apart? Proceedings SIGMIS-CPR'07. (April, 2007), 95-100.

[4] Foley, J., Technology Transfer from University to Industry. Communications of the ACM. 39, 9 (September 1996), 30-31.

[5] Chamberlain, S., Sharp, H., \& Maiden, Neil (2006) Towards a framework for integrating agile development and user-centred design. In: Extreme Programming and Agile Processes in Software Engineering: 7th International Conference, XP 2006 (Oulu, Finland, June 17-22, 2006), 143-153.

[6] Microsoft Visio. http://office.microsoft.com/enus/visio/default.aspx Last accessed Feb. 4, 2008

[7] Axure software. http://www.axure.com/ Last accessed Feb. 4, 2008. 